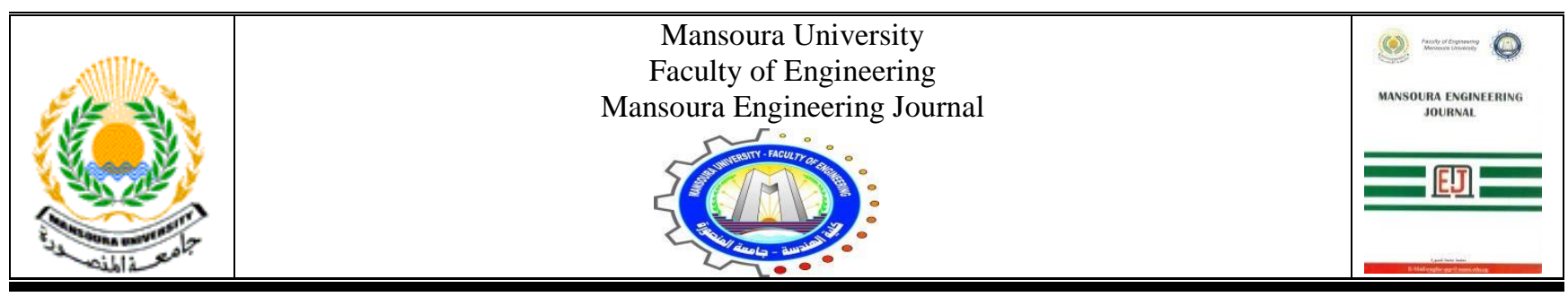

\title{
Investigating the Performance of Hot Mix Asphalt Modified with Chemical Additives
}

\author{
Samir Azmy, Hassan Youness, Ayman M. Othman and Mostafa Deep
}

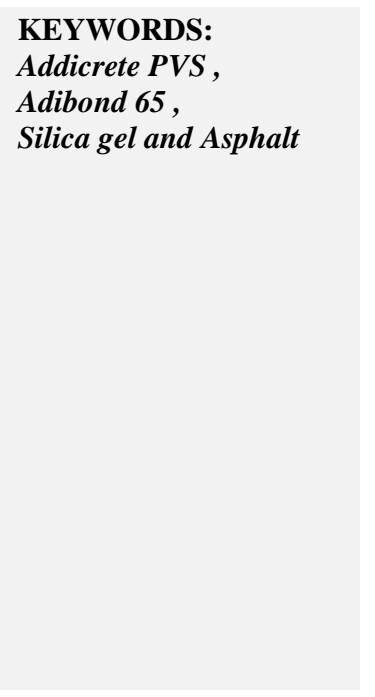

\begin{abstract}
The Egyptian roads suffer from many distresses, which depends to a significant extent on the mechanical properties of the asphaltic layer. Therefore, scientists and engineers are constantly trying to improve the mechanical properties of the asphaltic mixtures. One common method of improving the performance of asphaltic mixtures is the use of different types of additives. The objective of this research is to study the effect of using chemical additives on the mechanical properties of hot mix asphalt (HMA). Three chemical additives were used. The additives were Addicrete PVS, Adibond 65 and Silica gel, that were added with different ratios of 5, 10, 15 and $20 \%$ by the weight of optimum asphalt content in addition to the original mix. Marshall test, Indirect tensile strength test and Moisture susceptibility test were conducted on the investigated mixes. Testing results on the modified mixes were compared with the original mix. The results show that exploitation of Addicrete PVS and Silica gel at $10 \%$ content enhanced the worth of Marshall stability, Marshall stiffness, indirect tensile strength, TSR and improved the value of flow whereas decreased the value of bulk density compared to the control mix. Also, the results showed that the most effective content at that adding of Adibond 65 yielded the most effective results was $15 \%$.
\end{abstract}

\section{INTRODUCTION}

$\mathrm{T}$ THE most important properties of the bitumen mixture in the wearing course design is its ability to resist shoving and rutting under traffic. Therefore, stability should be high enough to handle traffic

Received: (26 October, 2020) - Revised: (17 January, 2021) - Accepted: (2 Feburary, 2021)

Corresponding Author: Samir Azmy is a Teaching Assistant at Civil Department, Higher Institute of Engineering and Technology, New Minya, El Minya, Egypt (e-mail: civileng.semsem@yahoo.com)

Hassan Youness is a Professor with Civil Department, Faculty of Engineering at Assuit University, Assuit, Egypt (e-mail: younes1955@yahoo.com)

Ayman Mahmoud Othman is a Professor with Civil Department, Faculty of Engineering at Aswan University, Aswan, Egypt (e-mail: amo802003@yahoo.com)

Mostafa Deep is a Professor with Civil Department, Faculty of Engineering at El-Minya University, El-Minya, Egypt (e-mail: $\underline{\text { m deep_2009@yahoo.com) }}$ adequately, but not higher than the traffic conditions required. The lack of stability in an asphalt mixture causes raveling and flow of the road surface. Flow is the ability of a hot mix asphalt (HMA) pavement to adjust to gradual settlements and movements in the subgrade without cracking [1,2]. There are different ways to improve asphalt mixture properties:

- First is constructing road pavement with higher thickness.

- Second is using different types of additives as a modifier.

Kwang et al. investigated the possibility of utilizing a polyester resin for reinforcing flexible pavements. The application of a thin-layer coating with a polymer, unsaturated polyester resin (UPR) on the surface of a laboratory-prepared unmodified asphalt concrete mixture was studied as a tensile reinforcement method for such material. Selected laboratory performance tests were conducted and the results were compared with those of a normal (uncoated) asphalt concrete mixture and a modified asphalt mixture. The polymer coating was found to be effective in improving Marshall Stability, tensile strength, and flexural strength of asphalt concrete 
mixtures [3]. Chen and Lin investigated the effect of cellulose, rock wool, and polyester fiber on the engineering properties of asphalt. The test results indicated that good adhesion between fiber and bitumen enhanced the load-carrying ability of asphalt-fiber mastics [4]. Putman and Amirkhanian compared the performance of Stone Matrix Asphalt (SMA) mixtures containing waste tire and carpet fibers with mixes made with commonly used cellulose and polyester fibers. The results revealed that the tire, carpet, and polyester fibers significantly improved the toughness of the mixtures, but no significant difference in permanent deformation or moisture susceptibility was found [5]. El-Hamarawy et al. investigated the effect of adding short fibers on the mechanical properties of asphalt concrete mixes. Marshall test, indirect tensile strength, and static creep test were performed on both control and fiber mixes to evaluate their performance. The test results indicated that the addition of wool, linen, and fibrin fiber exhibited an improvement in the mechanical properties of asphalt mixes [6].

Naglaa investigated the effect of adding PET in different concentrations $(11,12,13,14$, and $15 \%)$ by the weight of asphalt on the mechanical properties of asphalt concrete mixes. Marshall, indirect tensile strength, rutting, and bending tests were evaluated. The observed results were confirmed by the BISAR computer program [7]. Mustafa D.H and Naglaa Kamal studied the influence of resin modifier materials on the performance of HMA, two types of resin modifiers were selected. One was an Unsaturated Polyester Resin (UPR) and the other was an Epoxy Resin (ER). Also, unsaturated polyester resin mixed with 3\% epoxy resin (UPRER) was used according to test results, which gave preference to $3 \%$ additions [8]. Ahmed A. L. studied the effect of using polyethylene on the pavement properties. The higher value of Marshall stability occurred at $10 \%$ polyethylene content. Adding polyethylene increased mixture workability and efficiency of compaction for modified mixes [9]. Awanti et al. showed that the static indirect strength values for SBS modified asphalt concrete were higher in order of $49-101 \%$ when compared to conventional asphalt mixtures in the temperature range of $15-40^{\circ} \mathrm{C}$ [10]. H. M. Rasel et al. examined the properties of bitumen grade 80/100 mixed with PVC (2.5\% to $20 \%$ by weight of bitumen) at optimum bitumen content and checked the design criteria of bituminous mixes using this bitumen-PVC binder. The results indicated that the PVC scrap can be utilized to bitumen to obtain high strength mixes and to get better adhesion properties of bitumen [11]. D. Movilla-Quesada et al studied the Effects of Recycled Polyethylene Terephthalate (PET) on Stiffness of Hot Asphalt Mixtures (HMA). The results showed that incorporating this polymeric additive provides greater stability, in addition to an increase in resistance to permanent deformations and fatigue, compared to a "traditional" mixture [12]. Z. Dehghan et al utilized the glass after reaching the temperature of glass transition $\left(70^{\circ} \mathrm{C}\right)$, it gradually obtains crystalline properties, contributing to the stiffness of the asphalt mixture [13]. M. Karami et al find that using of cellulose or polyester fibers reduced the rigidity of the asphalt mixture by making it more flexible, reaching values below $5000 \mathrm{MPa}$ [14].Huayang $\mathrm{Yu}$ et al investigated the effect of modifying asphalt rubber mixtures with various warm mix asphalt on the workability and the mechanical properies. Five different WMA additives, including Evotherm-DAT, Evotherm-3G, Sasobit, 56\# paraffin wax and Aspha-min were used to conduct the experimental study.the result showed that a $16{ }^{\circ} \mathrm{C}$ reduction in construction temperature can be achieved after using the different additives[15].Mostafa Vamegh et al evaluated the effect of asphalt mixtures modified with SBR/PP polymer blends and SBS on the fatigure resistance. The results showed that using of polymer blends has improved the fatigue performance [16]. Ghada S. Moussa et al studied the effect of using high-density polyethyleneh [HDPE]on the moisture susceptibility of asphalt mixtures. The results showed that implementing HDPE as a binder-additive improved the binder-aggregates bonding and consequently higher moisture resistance was gained [17].

The research gap is Limited research studies have been investigated on the use of some materials that are commonly used as concrete modifiers and to ensure the suitability of their use in pavement.

The research objective is to study the effect of using different types of chemical additives on the performance of the hot mixed asphalt.

\section{The Research Methodology}

To achieve the objectives of this research work the following work tasks which are outlined in were conducted:

- Review the benefits of the different additives on pavement performance.

- Select the mix materials and the types of additives to be used in this study

- A conventional control mix designed using Marshall method was used with different types and amounts of each additive to find out the optimum percent of each modifier.

- The influence of the modified binder on the HMA properties and moisture susceptibility was studied through laboratory testing.

\section{MATERIALS}

\section{A. Aggregate}

The crushed limestone was used as a coarse aggregate, siliceous sand as a fine aggregate, and limestone dust as mineral filler. The aggregate gradation was selected according to one of the gradations of the Egyptian code 2008 (Dense gradation $4 \mathrm{C}$ ). The gradation of the combined aggregate along with the specification limits are presented in Fig.1. The nominal maximum aggregate size was $25 \mathrm{~mm}$. The bulk specific gravities of coarse aggregate, fine aggregate, and mineral filler used were $2.619,2.629$, and 2.631 respectively. The loss Angeles abrasion and absorption percent of coarse aggregate was $29.2 \%$ and $1.4 \%$ respectively. 


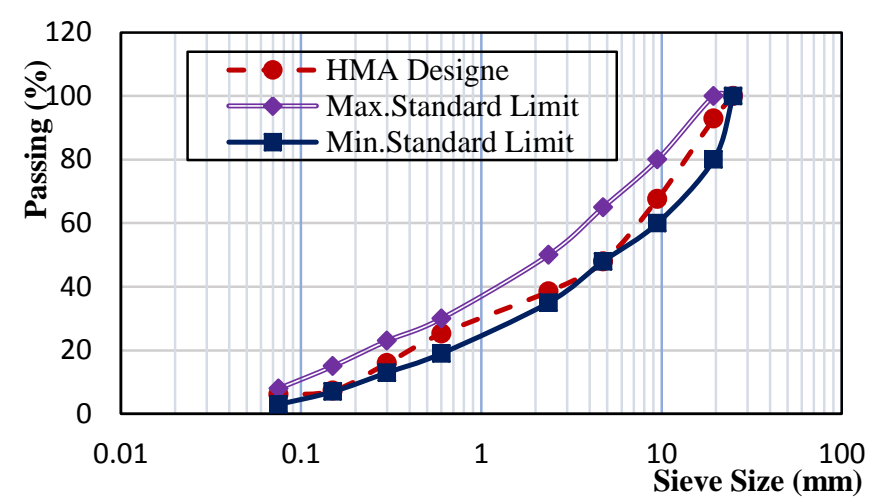

Fig.1. Mixture gradation

\section{B. Asphalt cement}

The asphalt cement used was AC 60/70. This asphalt material, supplied by El-Suez is the common asphalt grade used for asphalt pavement construction in Egypt. The physical properties of the asphalt cement used are shown in Table 1.

TABLE 1

PHYSICAL PROPERTIES OF BITUMINOUS MATERIALS ACCORDING TO E.R.B.A

\begin{tabular}{c||c||c||c||c}
$\begin{array}{c}\text { Test } \\
\text { No. }\end{array}$ & Test & $\begin{array}{c}\text { E.R.B.A. } \\
\text { designation } \\
\text { No. }\end{array}$ & Value & $\begin{array}{c}\text { Specification } \\
\text { limits }\end{array}$ \\
\hline $\boldsymbol{1}$ & $\begin{array}{c}\text { Penetration at } \\
25^{\circ} \mathrm{C}, 0.1 \mathrm{~mm}\end{array}$ & $\mathrm{~T}-205$ & 66 & $60-70$ \\
\hline $\mathbf{2}$ & $\begin{array}{c}\text { Softening } \\
\text { point }{ }^{\circ} \mathrm{C}\end{array}$ & $\mathrm{T}-208$ & 54.5 & $45-55$ \\
\hline $\mathbf{3}$ & Flash point ${ }^{\circ} \mathrm{C}$ & $\mathrm{T}-204$ & 221 & 240 \\
\hline
\end{tabular}

* E.R.B.A.: Egyptian Roads and Bridges Authority

\section{C.Additives}

Three types of chemical additives used in this work are Addicrete PVS, Adibond 65, and Silica gel. The properties of the additives are shown in Table 2 to Table 4 . 4. The contents of additives in asphalt mixtures were 5\%,10\%,15\%, and $20 \%$ by the weight of asphalt were used at O.A.C. The additives were mixed with asphalt binder at $110^{\circ} \mathrm{c}$ for 30 minutes.

TABLE 2

THE PROPERTIES OF ADDICRETE PVS [18].

\begin{tabular}{l||l||l}
$\mathbf{1}$ & density at $29^{\circ} \mathbf{c}(\mathbf{k g} / \mathbf{L})$ & $1.21 \pm 0.01$ \\
\hline $\mathbf{2}$ & Type & Superplasticizer \\
\hline $\mathbf{3}$ & Solubility & Soluble \\
\hline $\mathbf{4}$ & physical state & Brown liquid
\end{tabular}

TABLE 3

THE PROPERTIES OF ADIBOND 65 [18].

\begin{tabular}{|c|c|c|}
\hline 1 & Density at $27^{\circ} \mathrm{c}(\mathrm{kg} / \mathrm{L})$ & 1.01 \\
\hline 2 & The ratio of Solid Material & $44.50 \%$ \\
\hline 3 & Type & $\begin{array}{l}\text { Emulsion (Latex } \\
\text { Betadine Styrene) }\end{array}$ \\
\hline 4 & PH & 10.5 \\
\hline 5 & Solubility & soluble \\
\hline 6 & physical state & clear white liquid \\
\hline
\end{tabular}

TABLE 4

THE PROPERTIES OF SILICA GEL [19].

\begin{tabular}{l||l||l}
$\mathbf{1}$ & Molar weight at $25^{\circ} \mathbf{c}$ & $60.08 \mathrm{~g} /$ mole \\
\hline $\mathbf{2}$ & Chemical formula & $\mathrm{SiO}_{2}$ \\
\hline $\mathbf{3}$ & Solubility & Insoluble \\
\hline $\mathbf{4}$ & Physical state & Transparent beads
\end{tabular}

\section{EXPERIMENTAL WORK}

The coarse aggregate, fine aggregate, mineral filler, and asphalt cement were used to prepare the Marshall test specimens with $65 \mathrm{~mm}$ height and $101.6 \mathrm{~mm}$ diameter. The tested asphaltic concrete mixes were composed of $60 \%$ coarse aggregate, $35 \%$ fine aggregate, $5 \%$ mineral filler, and asphalt cement. According to the design mixture, the Optimum Asphalt Content (OAC) for control mixtures was 4.9\%.

\section{A. Marshall Tests}

Additives with different concentrations were added separately to the asphalt cement and 39 Marshall specimens were tested. After mixing hot aggregate with asphalt cement with chemical modifiers, samples were compacted using Marshall hammer with 75 blows /side to represent heavy traffic volume. Marshall test was conducted on both Control and chemicals modifiers mix to evaluate their performance. Marshall test properties for the control mix are illustrated in Table 5

TABLE 5

MARSHALL PROPERTIES FOR THE CONTROL MIX

\begin{tabular}{l||l} 
Mix Property & Value \\
\hline Asphalt Binder Specific Gravity, Gb & 1.020 \\
\hline Bulk Specific Gravity, Gmb & 2.365 \\
\hline Air Voids (\%) & 4.15 \\
\hline Voids in Mineral Aggregate, VMA & 13.502 \\
\hline Voids Filled with Asphalt, VFA & 79.98 \\
\hline Marshall Stability (kg) & 864 \\
\hline Marshall Flow (mm) & 2.75 \\
\hline Asphalt Content by Weight (\%) & 4.90
\end{tabular}

\section{B. Indirect Tensile Tests}

The stiffness modulus and the indirect tensile strength of HMA are often used to evaluate the relative quality of materials. The load was applied vertically in the vertical diametral plane of a cylindrical specimen of asphalt concrete through a curved loading strip. The ITS test is performed at $77^{\circ} \mathrm{F}\left(25^{\circ} \mathrm{C}\right)$ with a loading rate of $2 \mathrm{in} / \mathrm{min}$. [Standard Specifications 1995]. The measured load value at failure $(\mathrm{P})$ in Newton and the thickness of specimen (h) in $\mathrm{mm}$, were used to calculate the indirect tensile strength.

\section{Moisture Susceptibility Tests}

AASHTO accepted the Modified Lottman Test (AASHTO T-283) in 1985. It is a combination of the Lottman Test, and 
the Tunnicliff and Root Test. Six specimens are produced with air voids between six percent and eight percent for each additive content. The higher percentage of air voids helps to accelerate moisture damage on the cores. Two groups of three specimens are used. The first group is the control group. The second group is saturated between 55 and 80 percent with water and is placed in the freezer $\left(0^{\circ} \mathrm{F}\right.$ or $\left.-18^{\circ} \mathrm{C}\right)$ for 16 to 18 hours. The frozen cores then are moved to a water bath at $140^{\circ} \mathrm{F}\left(60^{\circ} \mathrm{C}\right)$ for 24 hours. After conditioning, the Resilient Modulus Test and/or ITS test are performed. the minimum Acceptable TSR used is 0.8 .

\section{RESULTS AND DISCUSSION}

\section{A. Marshall Test Results}

\section{Effect of Additives Type on Marshall Stability.}

Fig.2 shows the test results of Marshall stability versus additive content for the different types. It reveals that the stability increased with increasing additive content up to $10 \%$ for both Silica gel and Addicrete PVS while for Adibond 65 the increase in stability was up to $15 \%$ content respectively then the stability decreased with an increase in additive content. This result may come up because the additives increased the bond between aggregate particles consequently increased the stiffness of the mixture which made the specimen able to resist the external loads.

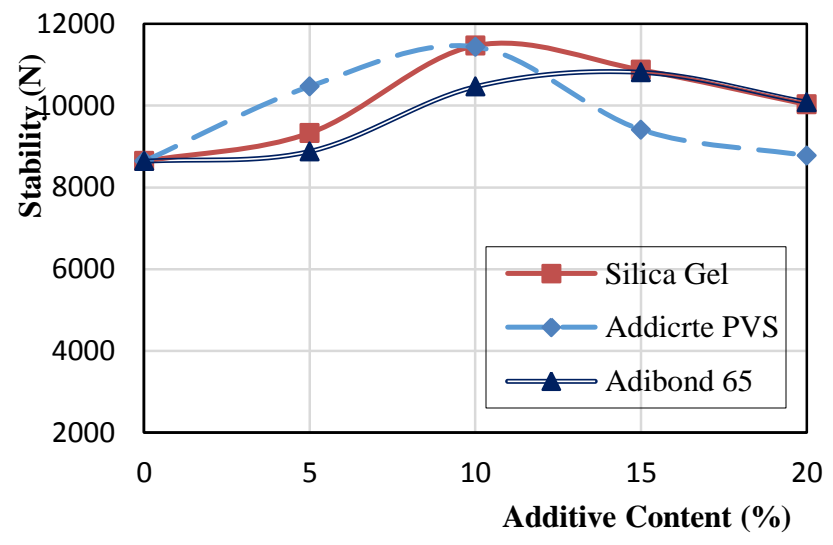

Fig.2. Effect of additives content on Marshall stability

2. Effect of Additive Types on Flow Values.

The flow results for different additives are shown in Fig.3. It is clear from the results that the flow values increased with increasing of additive content up to $10 \%$ for both Silica gel and Addicrete PVS while for Adibond 65 the increasing of the flow value was up to $15 \%$ additive content respectively then the value of flow decreased with any increasing of additive content. This may be due to the high stability values at these contents as shown in Fig.2.

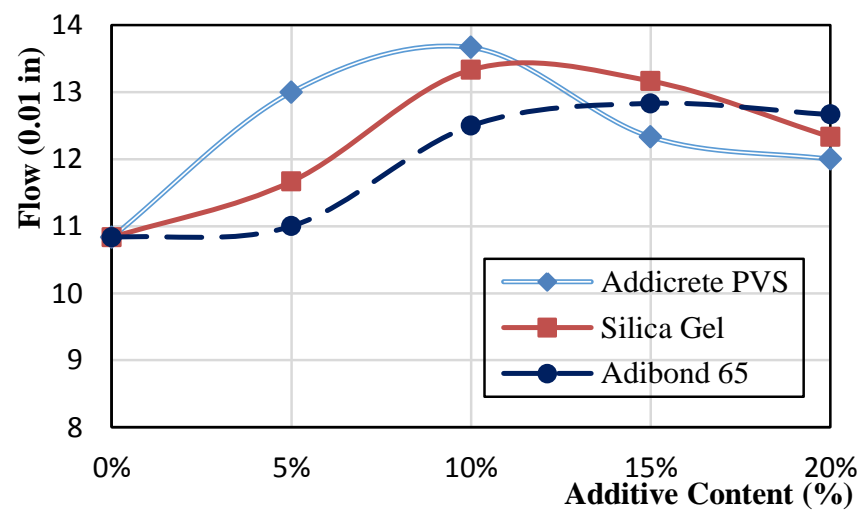

Fig.3. Effect of additives content on flow

\section{Effect of Additive Types on Bulk Density.}

The relationships between different additive contents and bulk density are illustrated in Fig. 4. It is clear from the results that the bulk density of modified samples decreased with the increase of additive content for both Addicrete PVS and Silica Gel while for Adibond 65 the value of bulk density decreased at $5 \%$ content then it returns to increase with an increase of additive content up to $15 \%$ to back again to decrease with increasing of additive content in the mix to $20 \%$. These results may become up due to the additives increased the viscosity of asphalt cement which consequently makes it doesn't fill all the voids in the mix. The highest value of bulk density was at $0 \%$ additive contents (original mix) this may be due to the high workability of the mixture and the low viscosity of the asphalt cement.

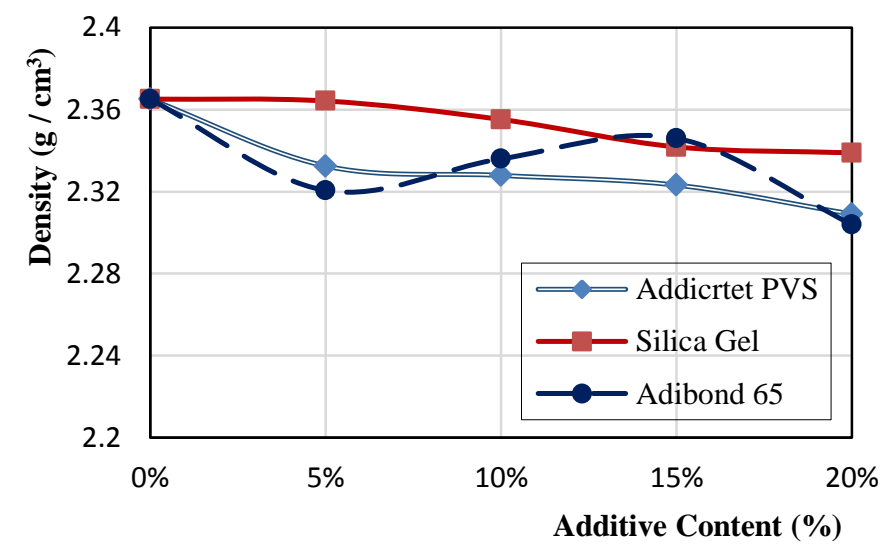

Fig.4. Effect of additives content on bulk density

\section{Effect of Additives Types on Air Voids.}

Fig.5 shows voids in total mineral aggregate (VTM) versus additives content. It reveals that the air voids increased with increasing the additive content for both Addicrete PVS and Silica Gel while for Adibond 65 the value of air voids decreased at $5 \%$ content then it returns to increase with increasing the additive content up to $15 \%$ to back again to decrease with increasing of additive content in the mix to $20 \%$. This may happen due to the high viscosity of the asphalt cement which decreased the workability of it to react with the 
mix component and that cleared form the low bulk density as shown in Fig .4. the lowest value of air voids was at $0 \%$ additive content (original mix) due to its high workability to mix consequently had high bulk density.

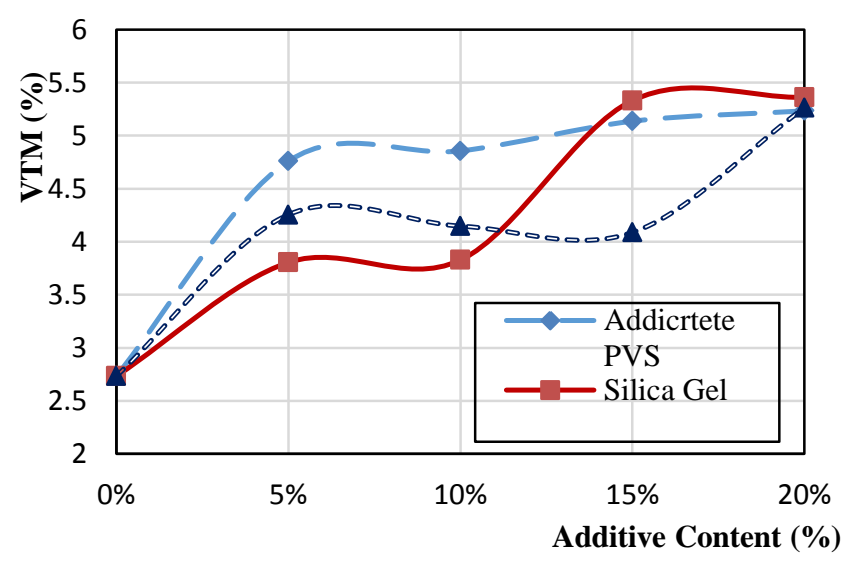

Fig.5. Effect of additives content on VTM

\section{Effect of Additives Types on Marshall Stiffness Modulus}

The relationships between different additive content and Marshall Stiffness Modulus (MS) are illustrated in Fig.6. It reveals that the (MS) increased with increasing the additive content up to $10 \%$ for both Silica gel and Addicrete PVS while for Adibond 65 the increasing of stiffness modulus (MS) was up to $15 \%$ additive content respectively then the value decreased with any increasing of additive content. This result may be due to the high values of Marshall stability of modified mixtures at these contents as shown in Fig.2.

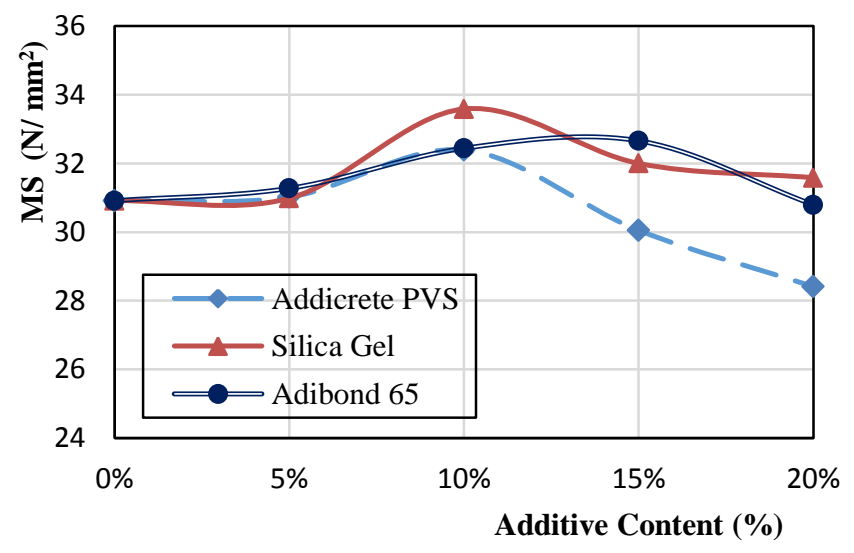

Fig.6. Effect of additives content on Marshall stiffness (MS)

\section{Effect of Additives Types on Marshall Quotient.}

The relationships between different additives content and Marshall quotient (MQ) are illustrated in Fig.7. The Marshall quotient (MQ) increased with increasing the additive content up to $10 \%$ for both Silica gel and Addicrete PVS while for Adibond 65 the increasing of Marshall quotient (MQ) was up to $15 \%$ additive content respectively then the value decreased with any increasing of additive content. This result may come up because adding the additive to the mix increased the stability values and the stiffness modulus as shown in Fig.2 and Fig.6 respectively.

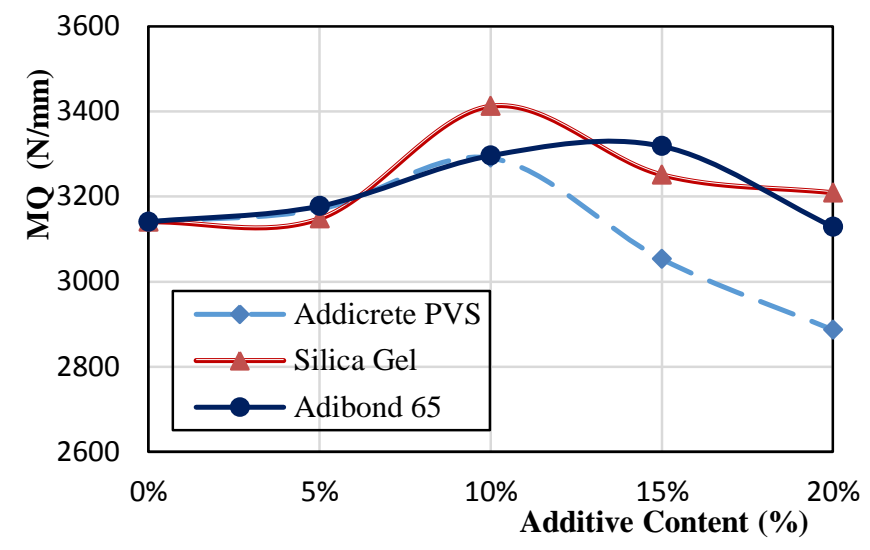

Fig.7. Effect of additives content on Marshall Quotient (MQ)

\section{B. Indirect Tensile Test Results}

1. Effect of Additives Types on Indirect Tensile Test Results.

Figure 7 shows the relations between different additives content and Indirect Tensile Strength (ITS). The results unconcealed that ITS increased with increasing of additive content up to $10 \%$ for both Silica gel and Addicrete PVS while the increasing of ITS was up to $15 \%$ content for Adibond 65 then the value decreased with any increasing of additive content. This result may come up because adding the additive to the mix increased the ability of the mixture to resist the existing loads and that clear from the high values of stability at these contents as shown in Fig. 2.

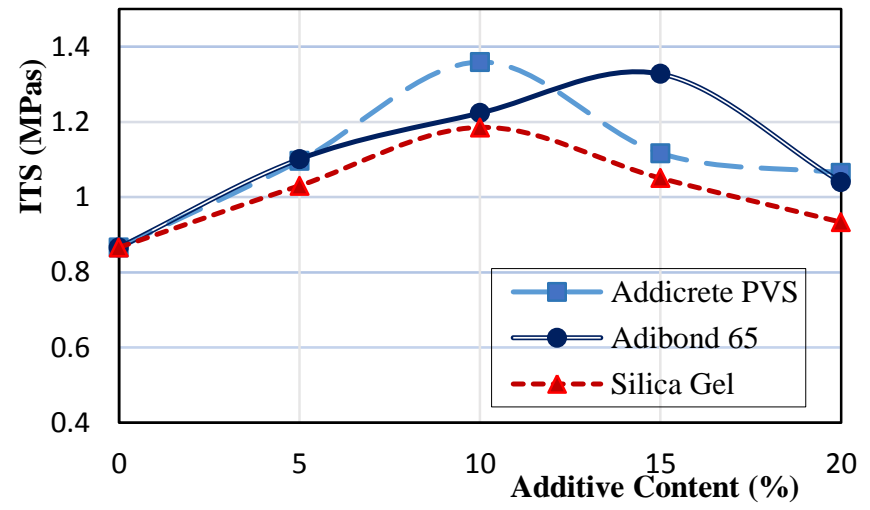

Fig.8. Effect of additives content on ITS

\section{Effect of Additives Types on Failure Strain}

The failure strain results for different additives content are shown in Fig.9. It is clear from the result that the failure strain values increased with increasing of additive content up to $10 \%$ for both Silica gel and Addicrete PVS while for Adibond 65 the increasing of the failure strain value was up to $15 \%$ additive content respectively then the value decreased with increasing of additive content. This may be due to the high indirect tensile strength (ITS) values at this content as shown in Fig. 8 and this confirms the values of flow as shown in Fig.3 


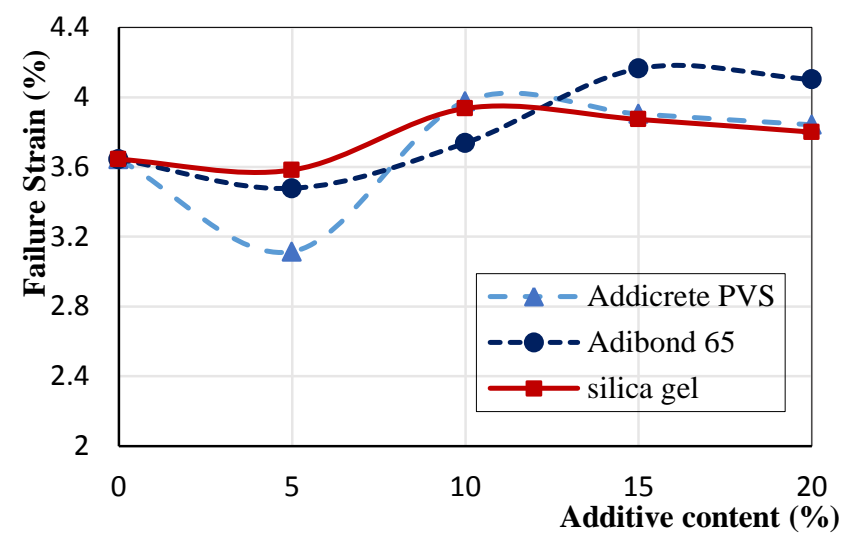

Fig.9. Effect additives content on failure strain

\section{Moisture Susceptibility Test Results}

\section{Effect of Additives Types on Tensile Strength Ratio.}

Fig.10 shows the relations between different additives content and Tensile Strength Ratio (TSR) for different types of additives. It clears that TSR increased with increasing of additive content up to $10 \%$ for both Silica gel and Addicrete PVS while the increasing of TSR was at $15 \%$ content for Adibond 65 respectively then the value decreased with any increasing of additive content. It was recommended that the minimum acceptable value TSR was 0.8. According to the acceptable value, the best content for adding Addicrete PVS and Silica Gel was $10 \%$ while for adding Adibond 65 was $15 \%$. This result may come up because adding the additive to the mix increased the ability of the mixture to resist the existing loads and that clear from the high values of indirect tensile strength at these contents as shown in Fig.8.

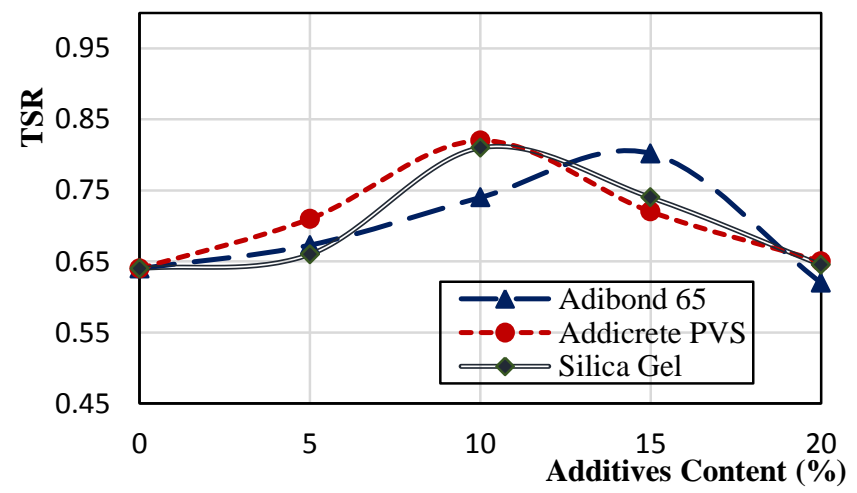

Fig.10. Tensile strength ratio (TSR) for different additive types at different contents

D. Comparison Between the Different Types of Additives According to Test Results

1. Marshall Test Results.

\subsection{Marshall Stability}

The relation between Marshall stability and the different types of mixtures are illustrated in Fig.11. The results showed that the stability increased with using different types of additives comparing with the original mix. Using Addicrete PVS and Silica Gel at $10 \%$ content increased the value of stability by $32.4 \%$ and $32.75 \%$ respectively. Also, using Adibond 65 at $15 \%$ increased stability by $25.2 \%$. It is clear from the results that using Silica gel had the highest value of increased instability.

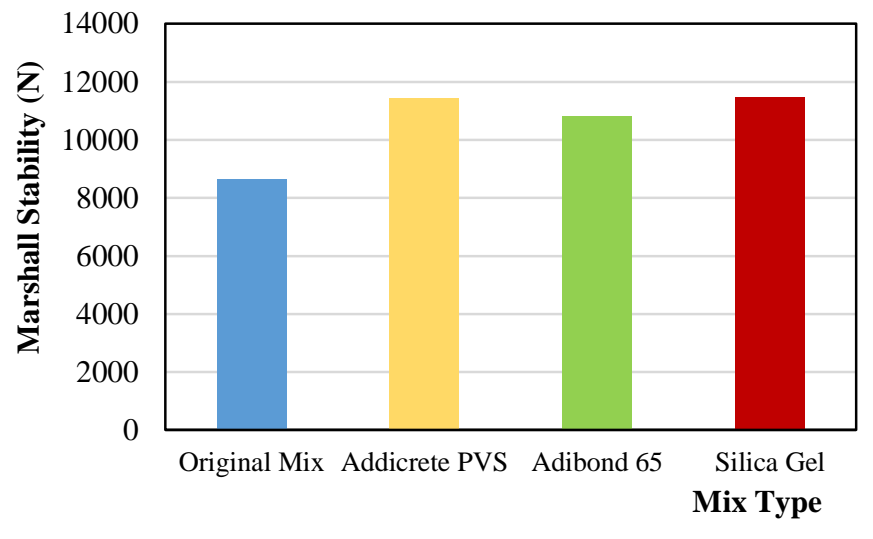

Fig.11.Marshall stability for different mixtures types

\subsection{Bulk Density}

Fig.12 illustrates the relationship between bulk density and the different types of mixtures. The results showed that the bulk density decreased for all types of additives than the control mixture. Using both Addicrete PVS, Adibond 65, Silica Gel and decreased the bulk density by $1.6 \%, 0.8 \%$, and $0.97 \%$ respectively in comparison with the control. The control mixture had the highest value of bulk density.

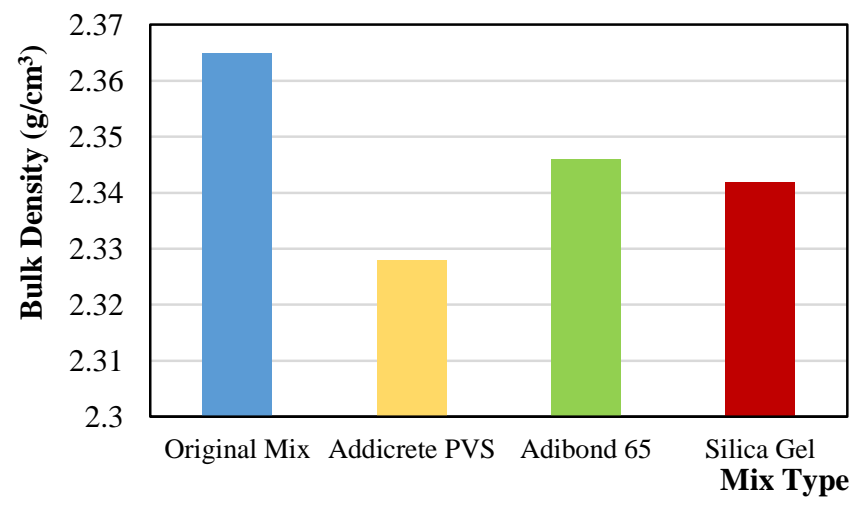

Fig.12. Bulk density for Different mixtures types

\subsection{Marshall Quotient (MQ)}

The relation between Marshall's quotient and the different types of mixtures is illustrated in Fig.13. The results showed that MQ increased with using different types of additives comparing with the original mix. Using Addicrete PVS and Silica Gel at $10 \%$ content increased the value of Marshall quotient by $4.8 \%$ and $5.65 \%$ respectively. Also, using Adibond 65 at $15 \%$ increased the value of MQ by $8.6 \%$. It is 
clear from the results that using Silica gel had the highest value Marshall Quotient

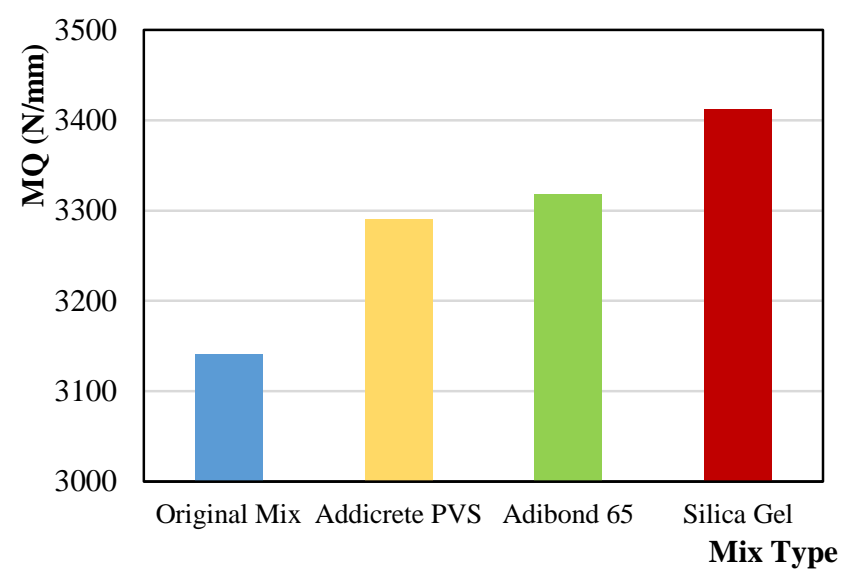

Fig.13. Marshall Quotient (MQ)versus mix type

\subsection{Marshall Stiffness (MS)}

Fig.14 shows the results of Marshall Stiffness for the different types of mixtures. The results showed that MS increased with using different types of additives comparing with the original mix. Using Addicrete PVS and Silica Gel at $10 \%$ content increased the value of Marshall stiffness by $4.8 \%$ and $5.65 \%$ respectively. Also, using Adibond 65 at $15 \%$ increased the Marshall stiffness by $8.6 \%$. It is clear from the results that using Silica gel had the highest value Marshall Quotient.

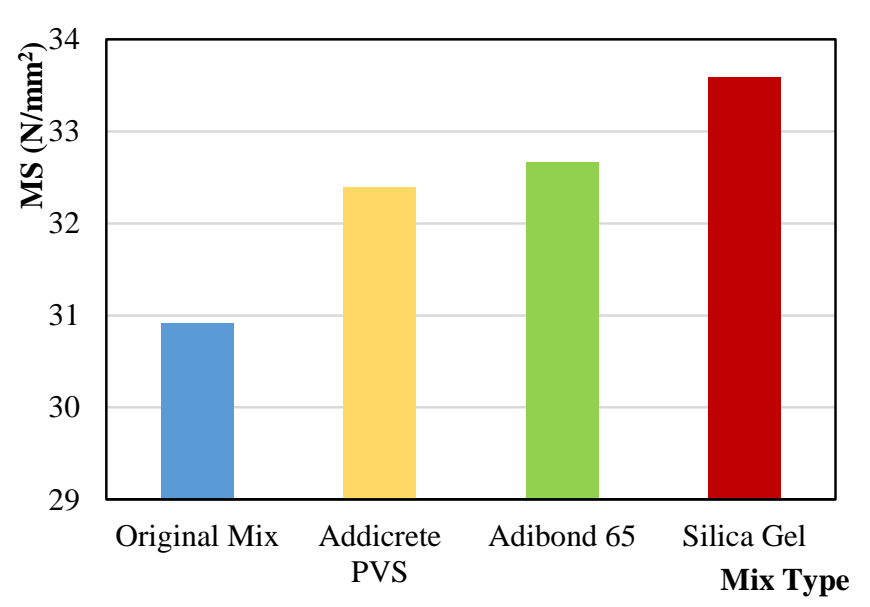

Fig.14. Marshall stiffness (MS) versus mix type

\section{Indirect Test Results}

\subsection{Indirect Tensile Strength (ITS)}

The relation between the indirect tensile strength (ITS) for the different types of mixtures were shown in Fig.15. The results showed that using different types of additives increased the value of ITS in comparing with the original mix. Using Addicrete PVS and Silica Gel at $10 \%$ content increased the value of ITS by $56.3 \%$ and $20.7 \%$ respectively. Also, using Adibond 65 at $15 \%$ increased the value of ITS by $40.2 \%$. It is clear from the results that the modified mixture with Addicrete PVS had the highest value of ITS.

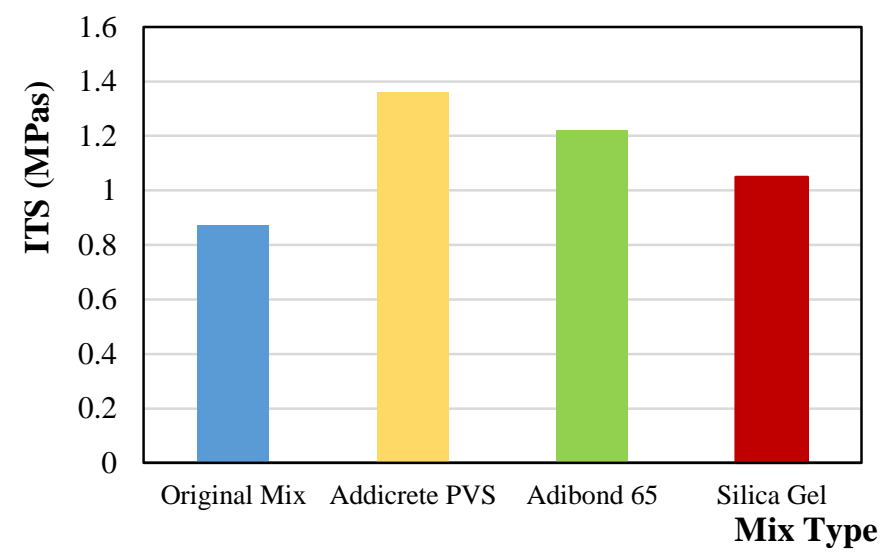

Figure 15. Indirect tensile strength (ITS) versus mix type

\section{Moisture Susceptibility Result}

\subsection{Tensile Strength Ratio (TSR)}

Fig.16 shows the relation between tensile strength ratio (STR) and the different types of mixtures. The results showed that the value of TSR increased with using different types of additives with different values with each one comparing with the original mix. It is clear from the results that using Silica Fume had the highest value of TSR than other additives.

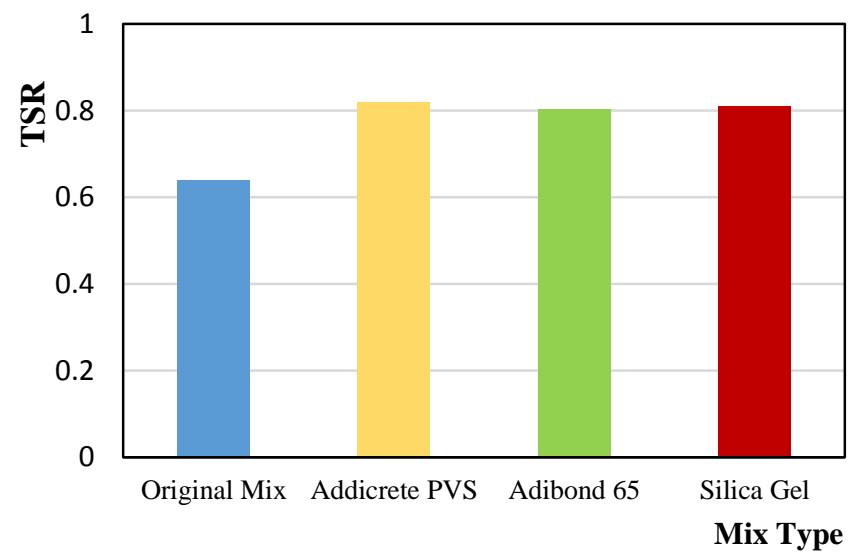

Figure 16. Tensile strength ratio (TSR) versus mix type

\section{CONCLUSION}

\section{A. Marshall Test results}

- The results showed positive effects when using these chemicals as modifiers to the asphalt mixture.It was concluded that the optimum content for adding Addicrete PVS and Silica gel was $10 \%$ while it was $15 \%$ for adding Adibond 65

- The results were unconcealed that exploitation Addicrete PVS and Silica gel at $10 \%$ content increased the stability worth of the mixture by $32.4 \%$ and $32.7 \%$ severally 
whereas exploitation Adibond 65 at $15 \%$ content increased the steadiness worth by $25.2 \%$ in scrutiny to the control mix.

- Using Addicrete PVS and Silica gel at $10 \%$ content augmented the worth of flow by $26.2 \%$ and $23 \%$ severally whereas the increasing ratio was $18 \%$ when using Adibond 65 with $15 \%$ compared to the control mix.

- The bulk density value decreased by $1.6 \%$ and $0.4 \%$ after using Addicrete PVS and Silica gel at $10 \%$ content respectively. Utilizing the Adibond 65 at $15 \%$ decreased the bulk density value by $0.8 \%$.

- The values of VTM enlarged with increasing of Addicrete PVS, Silica gel, and Adibond 65 within the mixture.

- The results were unconcealed that exploitation Addicrete PVS and Silica gel at 10\% content increased the Marshall stiffness (MS) and Marshall Quotient (MQ) worth of the mixture by $32.4 \%$ and $32.7 \%$ severally whereas exploitation Adibond 65 at $15 \%$ content increased the worth by $25.2 \%$ in scrutiny to the control mix.

\section{B. Indirect Tensile Test Results}

- The optimum content at which adding the different additive was the same as observed from Marshall test results.

- The results were unconcealed that exploitation Addicrete PVS and Silica gel at $10 \%$ content enlarged the Indirect strength (ITS) worth by $56.9 \%$ and $36.8 \%$ severally whereas exploitation Adibond 65 at $15 \%$ content enlarged the value by $53.6 \%$ in comparison to the control mix.

- Using of Addicrete PVS and Silica gel at 10\% content augmented the worth of failure strain by $9.1 \%$ and $8 \%$ severally whereas the increasing ratio was $14.3 \%$ after

- utilizing the Adibond 65 with $15 \%$ content in scrutiny to the control mix.

\section{Moisture Susceptibility Test Results}

- Using different additive increase the resistance of the mixture against moisture damage comparing with the control mix

- Using Addicrete PVS and Silica gel at 10 percent content increased the worth of Tensile Strength ratio (TSR) by $28 \%$ and $25.3 \%$ severally. Also, adding Adibond 65 15\% content increased the TSR worth by $26.6 \%$.

\section{RECOMMENDATION FOR FUTURE WORK}

We recommend that in future research, consideration be given to some essential matters such as:

- Some of these materials are very expensive, which requires conduct a Life Cycle Cost Analysis

- It was observed when using these materials, the value of the bulk density of the mixture decreased

\section{REFERENCES}

[1] Kulog $\notin$ lu. N, (1999) "Effect of Astragalus on Characteristics of Asphalt Concrete", Journal of material in Civil Engineering vol.11 No.4,283-286.
[2] Hinisliglu, S. \& Agar, E. (2004) "Use of waste High Density Polyethylene as Bitumen Modifier in Asphalt Concrete Mix". Journal of Materials letters. vol. 58, 267-271.

[3] Kwang W. Kim, Yong-Churl Park and Kyu-SeokYeon, (1996) "Tensile reinforcement polymer coating. Construction and Building Materials.Vol. 10. No. 2. pp. 141-146.

[4] Chen Jianshiuh, Lin Kueiyi. (2005) Mechanism and Behavior of Bitumen Strength Reinforcement Using Fibers [J]. Journal of Materials Science, 40: 87-95.

[5] Putman B. J, Amirkhanian S. N. (2000) Utilization of Waste Fibers in Stone Matrix Asphalt Mixtures [J]. Resources, Conservation and Recycling, 42: 265-274.

[6] El-Hamrawy S., El-Baz, M. and Abdel-Baset, A. (2003). Fibers for Improving the Mechanical Properties of Asphalt Concrete Mixes.1st International Conference of Civil Eng. Science ICCES1. Vol.2.

[7] Naglaa, K. R., (2009) "The Use of Additives In Improved Pavement Mix Design", A thesis submitted to the University of Al-Minia for the Degree Doctor of Philosophy.

[8] M. D. Hashem and N. K. Rashwan. (March 2013) " The Influence of Resin Modifiers on The Performance of Hot Mix Asphalt ", pp. $867-$ 885 .

[9] Ahmed A.L,(2007) "Improvement of Marshall Properties of the Asphalt Concrete Mixtures Using the Polyethylene as Additive", College of Engineering, Basrah University, Basrah-IRAQ Eng. \& Technology, Vol. 25, No.3.

[10] Awanti, S.S.; Amarnath M.S.; and Veeraragavan, A. (2008)." Laboratory Evaluation of SBS Modified Bituminous Paving Mix". Journal of Material in Civil Engineering, 327-330.

[11] H. M. Rasel, M. N. Rahman and T. U. Ahmed, (2011) "Study of Effects of Waste PVC on the Properties of Bituminous Mixes", S-JPSET, ISSN: 2229-7111, Vol. 2, Issue 2.

[12] D. Movilla-Quesada, A.C. Raposeiras, and J. Olavarria (2019) " Effects of Recycled Polyethylene Terephthalate (PET) on Stiffness of Hot Asphalt Mixtures". Volume 2019, Article ID 6969826, 6 pages.

[13] Z. Dehghan and A. Modarres, "Evaluating the fatigue properties of hot mix asphalt reinforced by recycled PET fibers using 4-point bending test," Construction and Building Materials, vol. 139, pp. 384-393, 2017.

[14] M. Karami, H. Nikraz, S. Sebayang, and L. Irianti, (2018) "Laboratory experiment on resilient modulus of BRA modified asphalt mixtures," International Journal of Pavement Research and Technology,vol. 11, no.1, pp. 38-46.

[15] Huayang Yu, Zhen Leng, Zejiao Dong, Zhifei Tan, Feng Guo and Jinhai Yan (2018) "Workability and mechanical property characterization of asphalt rubber mixtures modified with various warm mix asphalt additives", Construction and Building Materials ,Volume 175, Pages $392-$ 401.

[16] Mostafa Vamrgh, Mahmoud Ameri and Sayed Farhad Chavosgian Naeni. (2019) "Performance evaluation of fatigue resistance of asphalt mixtures modified by SBR/PP polymer blends and SBS" Construction and Building Materials Volume 209, Pages 202-214.

[17] Ghada S. Moussa, Ashraf Abdel-Raheem and Talaat AbdelWahed,(2020)"Investigating the Moisture Susceptibility of Asphalt Mixtures Modified with High-Density Polyethylene “, Vol. 48, No. 5, PP. 765-782.

[18] CMB,Engineer Guide ,2002.

[19] http://wikipedia.org/w/index.

\section{Title Arabic:}

$$
\text { دراسة أداء الخلطات الاسفلتية الساخنه المعدلة باضافات كيميائية }
$$

\section{Arabic Abstract:}

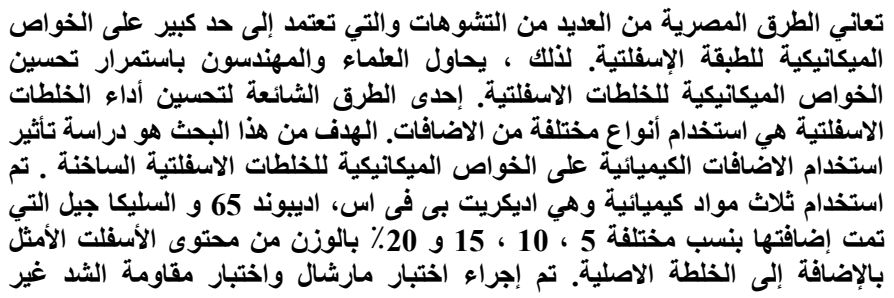


المباشر واختبار الحساسية للرطوية على الخلطات التي تم دراستها. تم مقارنة نتائج

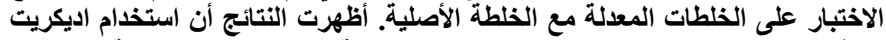
بى فى اس و السليكا جيل بمحتوى 10٪ عزز من قيمة ثبات مارشال ، صلابة مارشال ،
مقاومة الثد غير المباشرة ، نسبة مقاومة الثد و ايضا حسّن من قيمة الانسياب بينما

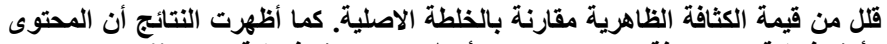

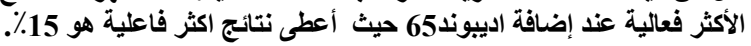

